\title{
Benefit Segments for Full-Time Undergraduate Students
}

\author{
JOHN H. CHURCH and DAVID W. GILLINGHAM*
}

\begin{abstract}
The purpose of this article is to present the results of a case analysis conducted at Laurentian University in Sudbury, Ontario. The objective of this case study was to identify the benefits sought by undergraduate students and to form meaningful groups, or segments, based upon these benefits. A sample of 427 full-time students at Laurentian University was used for this investigation. A questionnaire was used to gather information on the student, this included 19 questions using five-point Likert statements to measure the perceived benefits of a university education. Factor analysis was used to identify five underlying benefit dimensions which were subsequently labelled as: personal skill development; personal advancement; social pressure; learning and discovering; and intellectual development. Cluster analysis, based upon the factor scores, was used to form groups of students seeking similar benefits. Six groups, or segments, were formed and named as: self improvement; pressure; learning; self development; career; and continue to study favourite subject. These groups were found to have significantly different scores on a wide range of variables. Whilst this study was limited to the students at Laurentian University nevertheless university administrators should find this study useful as a case study of applying market segmentation to educational markets.
\end{abstract}

\section{RÉSUMÉ}

Le but de cet article est de présenter les résultats d'une étude de cas effectuée à l'Université Laurentienne de Sudbury, en Ontario. L'objet de cette étude était d'identifier les avantages que recherchent les étudiants et de classer ces derniers en groupes significatifs, ou segments, en tenant compte de ces avantages. L'échantillon étudié était composé de 427 étudiants inscrits à plein temps à l'Université Laurentienne. On a établi un questionnaire dans le but de recueillir certaines données sur les étudiants. Ce questionnaire contenait 19 questions

*School of Commerce and Administration, Laurentian University.

This research was funded by Laurentian University as a special project of Dr. F. Turner, then Executive Vice-President. 
auxquelles les étudiants devaient répondre à l'aide de l'échelle de Likert (barême allant de 0 à 5) afin d'évaluer avec précision les avantages que des études universitaires pourraient, d'après eux, leur procurer. A la suite d'une analyse factorielle, on a identifié cinq catégories sous-jacentes d'avantages que l'on a intitulées: développement des aptitudes personnelles; progrès individuel; influence sociale; apprentissage et découverte; et développement intellectuel. Puis on a fait une analyse typologique tenant compte des résultats obtenus pour regrouper les étudiants qui recherchaient les mêmes avantages. Six groupes, ou segments, ont été ainsi constitués et nommés d' après ces avantages: progrès individuel; pression; apprentissage; développement personnel; choix de carrière; et possibilité de continuer à étudier la matière qu'on préfère. On a trouvé que ces groupes avaient des scores qui variaient de façon significative, utilisant un grand nombre de variables. Même si cette étude ne se limitait qu'aux étudiants de l'Université Laurentienne, elle devrait néanmoins être utile aux administrateurs d'autres universités en tant qu'étude de cas présentant une façon de faire une segmentation de marché qui s'applique aux marchés universitaires.

University administrators are concerned about the students they serve as one of their publics. Students as the primary consumer group make purchasing decisions by deciding to go on to take a university education, choosing which universities to apply to, and by selecting a particular university and program in which to enrol. Certainly one measure of a university's success is its ability to attract the students it desires. University administrators do, therefore, have an interest in understanding more about how students make such decisions. One of the fundamental influences on their decisions must be the benefits they seek from a university education. If administrators can discover what these benefits are then they may be able to increase the number and quality of the applicants to their institutions. This paper describes how groups of students seeking similar benefits can be identified and described, it does this by applying certain techniques to survey results from Laurentian University. The process used and the overall findings from this case study, should be of interest to all educational executives, although the specific results will vary from institution to institution.

The grouping of potential customers according to the benefits they seek is called benefit segmentation. Each group so identified is called a market segment and the members of each group will seek similar benefits from the institution; however, members from different groups will seek different benefits.

The identification and description of market segments is one of the key inputs that university administrators require for strategic market planning. Once such segments have been discovered appropriate strategies can be designed to best match the organizations' resources to the needs of the market place. 


\section{APPLYING MARKETING THEORY TO UNIVERSITY MANAGEMENT}

Much has been written on the application of marketing theory and practice to university management. Kotler and Dubois (1974) pioneered this field in the United States and Doyle (1976) initiated much of the research in the United Kingdom. Despite extensive literature in the field relatively little work has been published on the benefits that students seek from a university education. Some authors have suggested the use of buyer behaviour models to help explain student choice behaviour. As Lynch and Hooley (1980) point out, however, the practical attempts to operationalize comprehensive buyer behaviour models have generally failed both in the business context and in the educational field. Benefit segmentation has been used reasonably successfully by Goodnow (1980) for adult learners in America, and by Saunders and Lancaster (1980) for undergraduates in the United Kingdom. The successful application of benefit segmentation relies upon being able to identify the benefits sought by students. These underlying factors are called benefit dimensions. Factor analysis is typically used to identify these dimensions and cluster analysis is used to form the segments. The application of factor and cluster analysis to the topic of benefit segmentation has been described by many authors and this methodology is reviewed by Wind (1978). Stewart (1981) provides a useful review of the application of factor analysis in marketing research. Punj and Stewart (1983) review the application of cluster analysis to marketing problems.

The benefits sought by students will influence their choice of institution and will be part of their selection criteria. Students evaluate the benefits they expect to receive from any given program/university combination and will make their choice with this in mind. University selection criteria have been investigated by numerous authors including Watts (1972) and Vaughn, Pitlik and Hansolia (1978). Heinlein (1977) and Cook (1977) provide useful insights into the attitudes of students and the dimensions by which students compare educational institutions. Traynor (1978), in a study of the benefits offered by colleges, examined the different perceptions held by students of colleges with regard to various benefit dimensions. He found that there were significant differences between colleges and that colleges did not offer the ideal set of benefits. Despite the extensive work published on this topic there is however, a lack of material which enables administrators to see the practical benefits of applying segmentation to their markets. This paper provides a case study of how segmentation was applied to the benefits sought by students at Laurentian University.

Laurentian University is a relatively small bilingual institution serving a large but thinly populated area in Northeastern Ontario. It provides a wide range of programs but does not have a faculty of medicine, nor does it have a full program in law. Whilst it enjoys a good reputation for many of its programs it certainly is not a high status university. 


\section{THE STUDY}

A review of the literature and in particular the work of Saunders (1980), Traynor (1978), Lynch (1980) and Watts (1972) leads the authors to a list of possible reasons why students chose to apply for a university education and of how they subsequently made their choice of university and program. This paper concentrates on the formulation of benefit segments constructed from the students' responses to a survey administered after they had entered Laurentian University.

\section{The Research Instrument}

The questionnaire was designed to gather information on the student, reasons this student had for applying for a university education and the choices made by this student with respect to programs and universities. Whilst the benefits sought were the major focus of the research instrument many other characteristics were measured including demographic and choice criteria. Such information often proves to be an important asset in the subsequent utilization of the benefit segmentation for planning purposes.

A series of 19 questions consisting of five-point Likert statements with possible responses ranging from "by far the most important" factor to "no, of no importance" measured students' perceived benefits of a university education. The responses to these questions were used as the input to the analysis of the benefit dimensions and the subsequent benefit segmentation.

A further series of 19 questions, also using a five-point scale, explored the importance students placed upon certain factors in making the decision of which university or universities and program(s) they should apply to for admission. The response categories were the same as for the previous questions. Responses to these questions were used to further describe the characteristics of the benefit segments.

Other questions collected information on demographic and some other decision dimensions.

\section{The Survey}

The survey was administered to a sample of first year classes covering all subject areas in the university. The cooperation of other faculty members ensured that it was completed during class time.

A total of 517 students completed the questionnaire and these responses were used for the basic analysis. The techniques used for benefit segmentation require complete responses and a total of 427 (that is 83 percent of the sample) were utilized for this phase of the analysis.

\section{Analysis}

A factor analysis was conducted on the 19 items relating to students' perceived benefits sought from a university education in order to construct the benefit 
dimensions. Cluster analysis of the factor scores was performed to yield possible student benefit segments. Factor analysis of the input to cluster analysis was performed to avoid redundancies in the intercorrelated variables (Morrison, 1967), to reveal the underlying structure of the benefit dimensions and to reduce the number of variables (Green and Tull, 1976). The factor analysis was performed on half of the data and repeated on the other half (split halves analysis) and the results were found to be consistent in both halves and indicated that the covariations among the 19 attributes were similar for both. Using eigenvalues greater than one, the same number of factors were extracted and the variables loaded heavily on the same factors in both split halves. The resultant factor scores were used as inputs to the K-Means Clustering program. A clustering level of six groups was chosen, based on a desire for maximum homogeneity (similarity) within groups and for simplicity.

\section{RESULTS}

The results of this analysis are shown in Tables 1 and 2 . The factor analysis for the whole data is shown in Table 1. The five factors shown make intuitive sense and account for $59 \%$ of the total variance. These five factors represent the underlying benefit dimensions sought by incoming full-time students. These dimensions we describe more fully below.

The segments were formed using cluster analysis. Table 2 shows the cluster means on each of the five factors. Since the original grouping was done on the factor scores the F-ratio used on these characteristics is less biased (Morrison, 1976). Only the significant results are presented in this paper but the cluster means are significantly different for 27 out of a total of 32 scaled variables, excluding those used in the factor analysis. The clusters are described in detail in a later section.

Discriminant analysis was used as another means to validate the cluster analysis. The student sample was split into two halves. For each half, a discriminant model to explain cluster membership was developed using the original variables taken as inputs to the factor analysis. A total of $78 \%$ of cases were correctly classified into their original clusters. This is significantly better than what one would expect by chance allocation.

\section{Benefit Dimensions}

The factors shown in Table 1 provide an interesting insight into the underlying benefit dimensions that students seek from an undergraduate university education. The prior research of Watts (1972), and Hooley and Lynch (1980) and others mentioned above indicated that it would be difficult to obtain good explanatory criteria. The resulting factors account for 59 percent of the variance. There is little overlap between the five factors with only factors 4 and 5 having "simply enjoy learning about new things" in common. 
FACTOR 1: PERSONAL SKILL DEVELOPMENT

This factor loaded heavily on all five variables related to developing skills and competencies together with the variable measuring developing greater personal insight.

FACTOR 2: PERSONAL ADVANCEMENT

This factor is composed of variables measuring the desire for an improved standard of living, the desire for career opportunities and simply wanting a degree. It is likely that wanting a degree is also related to desire for improved social status.

\section{FACTOR 3: SOCIAL PRESSURES}

The variables which compose this factor are not homogenous in that an individual is unlikely to rate them all in a similar manner. However, each variable represents some form of social pressure.

\section{FACTOR 4: LEARNING AND DISCOVERING}

This factor loaded heavily on variables measuring the desire for greater personal insight, learning about new things and wanting to meet new and interesting individuals. It also loaded heavily on the variable which measured whether the students were seeking to delay decision making until they had had time to discover more about their interests and career plans.

\section{FACTOR 5: INTELLECTUAL DEVELOPMENT}

The variables which constituted this factor consisted of those which measured whether students wanted to study their favourite subject, whether they wanted to increase knowledge and understanding, and whether they enjoyed learning about new things.

\section{Student Benefit Segments}

Six student benefit groupings (hereafter referred to as clusters) were identified by this research. Each of these is described in detail below. Additionally, Table 2 shows for each of these benefit segments the loading (i.e. importance weighting) placed on each of the five benefit dimensions or factors previously described.

In the descriptions and discussion which follows a number of abbreviations are used. MIF stands for most important factor, VIF for very important factor and MIF/VIF means most important or very important factor, that is the percent of a relevant cluster who rated the factor as most important or as very important.

In all cases, where a comparison is made the comparison is between an outcome for the relevant group versus the average outcome for all groups excluding the relevant group.

The description of each cluster includes the size of the group entering Laurentian, a brief snapshot of the group, important demographic characteristics 
of the group, a listing of those benefits of particular importance to the group, an indication of important factors emphasized by this group in deciding where to apply for university admission and an indication of this group's most favored areas of study.

In each case, all variables were tested for significance against the clusters using ANOVA. All variables reported have $F$ ratios significant at $p<0.005$. The overall multivariate $F$ ratio for scaled variables is significant at $p<0.001$.

\section{CLUSTER NO. 1: SELF IMPROVEMENT}

Size of this Group Entering Laurentian

This is the largest group of students accounting for $24.3 \%$ of those entering Laurentian.

\section{Brief Description}

Interested in both intellectual and personal advancement, this group is composed of students who most closely resemble traditional views of what are "ideal, seemingly well motivated" students.

\section{Demographic Characteristics}

Members of this group are more likely to be female, by comparison with all other groups, $(61.7 \%$ vs $46.6 \%)$ with slightly better grades (68.8\% have high school averages exceeding seventy percent vs $64.6 \%$ ). They come from higher income families and their parents are more likely to provide financial help.

\section{Important Benefits Sought in Deciding to Pursue a University Education}

They place much greater than average importance on learning (e.g. $89.7 \%$ indicated that "increasing their knowledge and understanding in an academic field" was the MIF/VIF vs $54.9 \%$ ) and skill development factors (e.g. 55.1\% indicated that "improving their problem solving skills" was the MIF/VIF vs $40.0 \%$ ), on career related factors (e.g. "opening up career opportunities" was rated the MIF/VIF by $86.0 \%$ of this group vs $59.3 \%$ ), on improving their standard of living (67.3\% MIF/VIF vs $54.1 \%)$ and on the status related to receiving a degree (43.0\% MIF vs $15.3 \%$ ) and being viewed as an educated person (24.3\% MIF/VIF vs $10.8 \%)$.

\section{Important Factors in Determining where to Apply for University Admission}

They place greater importance on the university's overall academic quality and reputation and on the university's quality and reputation in their desired program of studies. They are less likely to be influenced by which university their friends have chosen to attend.

\section{Most Favored Programs}

Nursing and Translation 
Table 1

Factors Underlying the Benefits Sought from a University Education: The Benefit Dimensions

\begin{tabular}{|c|c|c|}
\hline $\begin{array}{l}\text { Factor Name } \\
(\% \text { Variance })-\end{array}$ & $\begin{array}{l}\text { Benefit Attributes Loading on } \\
\text { this factor }\end{array}$ & $\begin{array}{l}\text { Variable } \\
\text { Loadings }\end{array}$ \\
\hline $\begin{array}{l}\text { 1. Personal } \\
\text { skill } \\
\text { development } \\
(21.2 \%)\end{array}$ & $\begin{array}{l}\text { Wanted to develop competencies } \\
\text { and skills in: } \\
\text { - interpersonal } \\
\text { - expression and communication } \\
\text { - intellectual and problem solving } \\
\text { - creativity } \\
\text { - leadership and organization } \\
\text { Wanted to develop greater personal } \\
\text { insight. }\end{array}$ & $\begin{array}{l}0.886 \\
0.867 \\
0.838 \\
0.795 \\
0.781 \\
0.496\end{array}$ \\
\hline
\end{tabular}

2. Personal To achieve an improved financial 0.775 advancement standard of living.

$(11.5 \%)$ To open up a much larger number of 0.773 career opportunities.

3. Social Not keen to go but felt pressure 0.712 pressures to go to university. (10.4\%) Wanted to get away from home. 0.633 Wanted others to see me as an 0.572 educated person. 


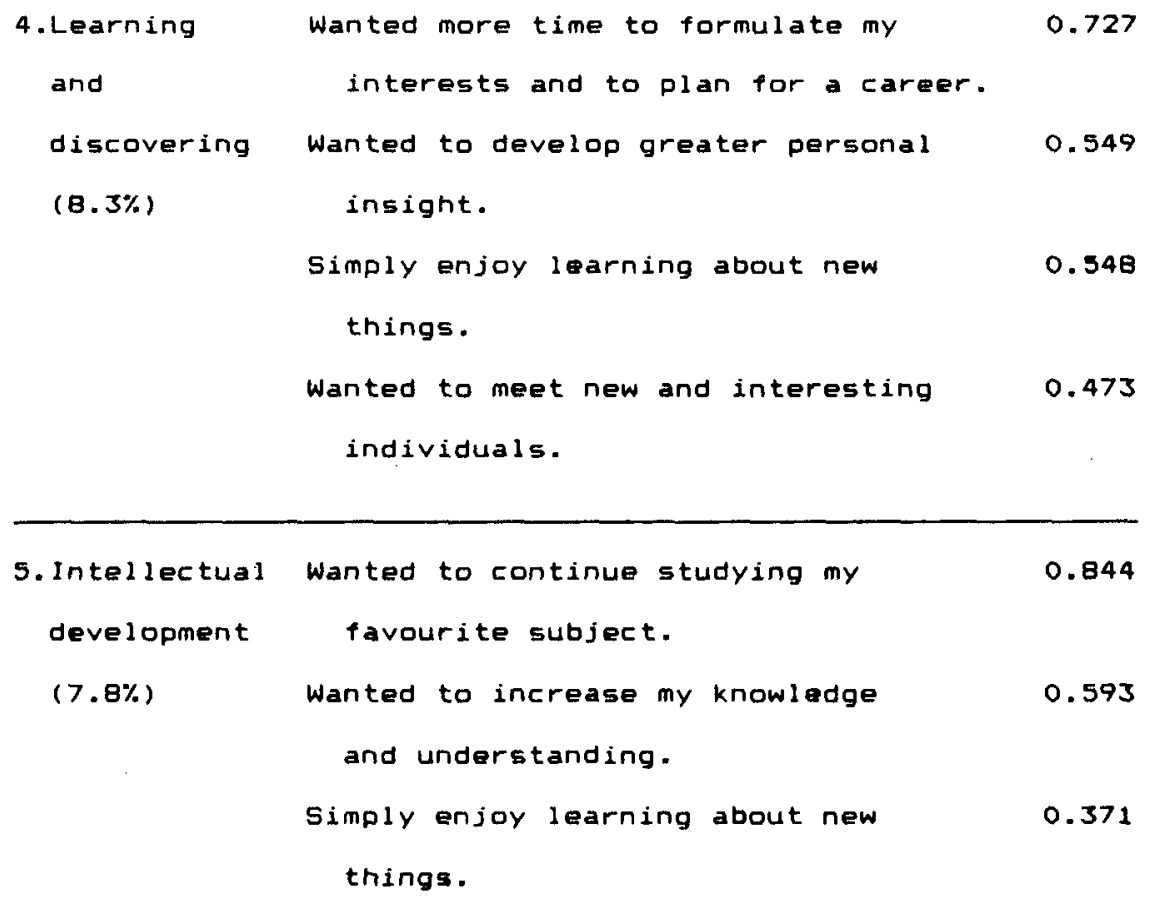

CLUSTER NO. 2: PRESSURE

\section{Size of this Group Entering Laurentian}

Twelve point four percent of students entering Laurentian fall into this group.

\section{Brief Description}

Not a very homogeneous group, the common element is the emphasis on social pressure. This pressure may exhibit itself in many forms.

\section{Demographic Characteristics}

This group tends to be dominated by young ( $87.3 \%$ between 17 and 21 years of age vs $83.2 \%$ ), single (98.2\% vs $94.1 \%$ ), males $(61.8 \%$ vs $48.9 \%)$. They come from rural areas (42.4\% live at least 50 miles from closest city vs $32.6 \%$ ). Academically, they tend to be under achievers $(45.4 \%$ have a less than 70 percent high school average vs $32.0 \%$ ) and less motivated (only $27.3 \%$ intend to pursue studies beyond the bachelor's level vs $39.4 \%$ ). 
Important Benefits Sought in Deciding to Pursue a University Education "Not keen but felt pressure from parents or other relatives to go to university" was listed as the MIF/VIF by $36.4 \%$ of this group vs an average of $1.5 \%$ for all other groups. Meeting new and interesting people was also an important factor $(36.4 \%$ MIF/VIF vs $12.1 \%$ ). Pressure also manifests itself in their desire "to be seen as an educated person" (30.9\% MIF/VIF vs $11.5 \%)$. Pressure may also be associated with their desire to improve their standard of living $(70.9 \%$ MIF/VIF vs $55.1 \%)$.

Aside from pressure related factors, this group places greater importance on "wanting more time to discover career interests and to formulate career plans" (25.5\% MIF vs $14.0 \%$ ).

Important Factors in Determining where to Apply for University Admission Members of this group tend to spend more time in choosing a program of studies to pursue, and place more importance on the advice of others, on the cost of attending various universities, on the likelihood of receiving financial assistance, on the likelihood of being admitted to the university and desired program of study, on location suitability, on overall university size and class size, on attending the same university as friends or relations, on the likelihood of meeting new and interesting people, on the language of instruction, and on the availability of facilities (residence and athletic).

\section{Most Favored Programs}

Arts, Engineering and Physical Education

CLUSTER NO. 3: LEARNING

Size of this Group Entering Laurentian

Another fairly small though significant group accounting for 11.0 percent of entering students.

\section{Brief Description}

These students are interested in learning for learning's sake without concern for personal advancement.

\section{Demographic Characteristics}

This group has an overweighting of females ( $60.4 \%$ vs $48.4 \%$ ) of higher academic achievement ( $27.1 \%$ have high school averages exceeding 80 percent vs $19.3 \%$ ) and higher academic objectives (13.2\% intend to go on for their Ph.D. vs $7.3 \%$ ).

\section{Important Benefits Sought in Deciding to Pursue a University Education}

Students in this group place somewhat more importance on learning factors such as increasing their knowledge and understanding (73.0\% MIF/VIF vs $61.0 \%$ ), pursuing their favourite subject $(50.0 \% \mathrm{MIF} / \mathrm{VIF}$ vs $38.4 \%)$ and enjoy learning about new things (45.9\% MIF/VIF vs $24.1 \%$ ). They also want to develop greater personal insight (43.8\% MIF/VIF vs $24.8 \%$ ). The acquisition and development of 
Table 2

Student Benefit Segments: Cluster Means on Benefit Dimensions

Cluster Name

Benefit Dimensions: Factors

\begin{tabular}{lllll}
\hline 1 & 2 & 3 & 4 & 5 \\
\hline
\end{tabular}

1. Self

$+0.258(+0.656) \quad-0.032 \quad-0.175 \quad(+0.979)$

improvement

$\begin{array}{llllll}\text { 2.Pressure } & +0.162 & -0.248 & (+1.791) & +0.277 & -0.305 \\ 3 . \text { Learning } & +0.087 & (-1.327) & -0.286 & (+0.610) & (+0.429) \\ 4.5 e 1 f & (+0.855) & +0.152 & (-0.543) & +0.300 & (-0.811)\end{array}$

development

$\begin{array}{llllll}\text { 5. Career } & (-1.101) & (+0.571) & -0.196 & +0.104 & (-0.413) \\ \text { 6.Favourite } & -0.293 & (-0.924) & -0.251 & (-1.283)+0.199\end{array}$

subject

Notes. All means over 0.4 have been enclosed in brackets. The benefit dimensions are described in Table 1.

skills and meeting new people are important to this group but clearly not of primary concern.

Career related factors and standard of living factors are of very little importance (e.g. only 10.4\% listed "improve standard of living" as MIF/VIF vs 61.4\%).

Important Factors in Determining where to Apply for University Admission They spend less time deciding to apply for university admittance and in choosing a program, but spend more time choosing which university to attend. They place less importance on the university's reputation, the likelihood of being admitted and the suitability of location. They also place less importance on attending the same university as their friends and were less anxious at the prospect of attending university.

Most Favored Programs

Arts and Social Work 
CLUSTER NO. 4: SELF DEVELOPMENT

Size of this Group Entering Laurentian

This is the second largest group of students, representing 22.0 percent of those entering Laurentian.

\section{Brief Description}

Such students place substantial importance on skills development and seek to discover and experience life. Unlike the "Self Improvement" and "Learning" groups, such students are not motivated by intellectual development (i.e. studying their favourite subject or increasing their knowledge and understanding in a particular academic field). Unlike the "Learning" group, personal advancement is of some importance but not nearly so important as it is for the "Self Improvement" and "Career" groups.

\section{Demographic Characteristics}

Such students are more likely to be male (57.9\% vs $48.6 \%)$, but have other characteristics very similar to the average student population.

\section{Important Benefits Sought in Deciding to Pursue a University Education}

As previously indicated such students place very heavy importance on the development of a wide variety of general skills (e.g. the development of expression and communication skills $(89.5 \% \mathrm{MIF} / \mathrm{VIF}$ vs $40.8 \%)$, of problem solving skills $(75.8 \%$ vs $35.7 \%)$, of interpersonal skills $(72.6 \%$ vs $31.3 \%)$, of leadership and organizational skills ( $72.6 \%$ vs $35.0 \%)$, and of creativity skills $(60.0 \%$ vs $28.2 \%)$ ). Coupled with this desire to improve skills is the desire to achieve greater personal insight (44.2\% MIF/VIF vs $22.6 \%$ ).

They also place heavy importance on having more time to discover career interests and to formulate career plans (61.1\% MIF/VIF vs 38.6\%). Additionally, they feel a university education would open up more career opportunities $(70.5 \%$ MIF/VIF vs $63.5 \%$ ).

Only 1.1 percent indicate wanting to pursue their favourite subject as the most important factor vs 14.0 percent (14.8\% MIF/VIF vs $45.0 \%$ ). Pressure factors are much less important.

Important Factors in Determining where to Apply for University Admission. Such students spend more time deciding to apply for university and choosing their program of studies. They place more importance on university reputation and less importance on attending the same university as other people they know. They are more anxious about the prospect of attending university.

\section{Most Favored Programs.}

Teaching and Sports Administration. 
CLUSTER NO. 5: CAREER

Size of this Group Entering Laurentian.

The third largest group representing 21.1 percent of incoming students.

\section{Brief Description.}

Interested in pursuing personal advancement without regard to intellectual or personal development.

\section{Demographic Characteristics.}

This group is composed predominantly of young ( $94.6 \%$ are 17 to 21 years of age vs $81.5 \%$ ), single ( $98.9 \%$ vs $93.6 \%$ ), English speaking ( $85.7 \%$ vs $74.3 \%$ ) males $(63.4 \%$ vs $47.5 \%)$ with higher income parents.

Important Benefits Sought in Deciding to Pursue a University Education.

Students in this group seek an improved standard of living (77.4\% MIF/VIF vs $52.3 \%$ ), greater career opportunities (86.0\% MIF/VIF vs $60.2 \%$ ), and desire more time to discover career interests $(49.5 \% \mathrm{MIF} / \mathrm{VIF}$ vs $41.3 \%)$. They place very low importance on the development of personal insight $(7.5 \% \mathrm{MIF} / \mathrm{VIF}$ vs $30.7 \%)$ or on development of general skills (e.g. only $3.2 \%$ indicate the development of improved problem solving skills is either a MIF/VIF vs 52.0\%). They also attribute very low importance to learning related factors and pressure related factors.

Important Factors in Determining where to Apply for University Admission.

Such students spend more time in deciding what program to pursue and whether or not to apply for university admission. They place less importance on the university's academic quality, the cost of attending, the language of instruction, and the size of classes, although they prefer smaller classes. They also place less importance on the likelihood of meeting people, attending the same university as their friends, social atmosphere and residence facilities.

Most Favored Programs.

Commerce, Sciences and Translation.

CLUSTER NO. 6: CONTINUE TO STUDY FAVOURITE SUBJECT

Size of this Group Entering Laurentian.

Though the smallest group, it still accounts for a sizable 9.1 percent of entering students.

\section{Brief Description.}

Not particularly interested in any benefits, members of this group seem simply to be pursuing their favourite subject. They want to have some intellectual 
development whilst avoiding broad based learning and anything to do with personal advancement.

\section{Demographic Characteristics.}

This group has an unusually large proportion of French speaking $(25.0 \%$ vs $12.0 \%)$, older $(30.8 \%$ over 21 years of age vs $15.1 \%)$, married $(12.8 \%$ vs $3.4 \%$ ) women $(59.0 \%$ vs $48.8 \%)$. Laurentian is their closest university and they tend to receive little or no financial support from their parents.

\section{Important Benefits Sought in Deciding to Pursue a University Education.}

Fifty-five (55.0) percent of this group lists pursuing their favourite subject as the MIF/VIF vs $38.1 \%$ average for other groups. They may even go on for a Ph.D. $(10.8 \%$ vs $7.5 \%)$, but, they don't place particular value on the personal growth and development accompanying: (1) discovering or experiencing new subject matter (e.g. only $10.0 \%$ list "enjoy learning about new things as the MIF/VIF vs $27.5 \%$ ), (2) learning about themselves (only $2.5 \%$ rate "developing greater personal insight" as the MIF/VIF vs $27.3 \%$ ), or (3) developing any of the various personal skills.

Additionally, they very much downplay career related factors such as more time $(50.0 \%$ said it plays "no role" vs $6.1 \%)$ or to open up career opportunities $(10.0 \%$ MIF/VIF vs $69.3 \%$ ). They also de-emphasize standard of living improvement, pressure related variables and any desire to meet new people.

Important Factors in Determining where to Apply for University Admission. They place less importance on a wide range of academic and other factors, placing greater importance only upon university size. They prefer large class sizes.

\section{Most Favored Programs.}

Social Work, Teaching and Physical Education.

\section{SERVING THE VARIOUS BENEFIT SEGMENTS - AN EVALUATION OF LAURENTIAN UNIVERSITY}

Successfully competing in the market place invariably means developing a proper product, price, promotion and place (distribution) strategy. Such a strategy must appropriately address the needs (sought after benefits) of the potential customer groups.

For Laurentian University, one of 15 Ontario universities, price is governmentally controlled and place, with a few minor exceptions, is also virtually uncontrollable. In the short to medium term, only the product itself and its promotion can be altered significantly by the institution in any attempt to improve its competitive position, should it desire to do so.

Given an understanding of the benefit segments which exist and of the importance of various benefits and benefit dimensions, Laurentian's management 
Table 3

Evaluation of Laurentian's Product and Promotion Mix for Each of

the Six Benefit Segments

\begin{tabular}{lll}
\hline & \multicolumn{2}{c}{ Evaluation of } \\
\cline { 2 - 3 } & Product & Promotion \\
\hline Self Improvement & Fair & Poor \\
Pressure & Poor & Good \\
Learning & Good & Good \\
Self Development & Poor & Very Poor \\
Career & Fair & Poor \\
Favourite Subject & Good & Good \\
\hline
\end{tabular}

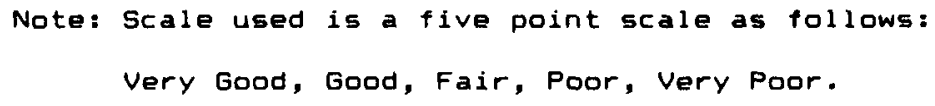

can now evaluate how well matched its product offerings and the promotion of those offerings are to the identified benefit segments.

The authors present some selected findings below. The approach used is to evaluate how well overall Laurentian serves each of the six benefit clusters. The evaluations which follow are solely those of the authors.

The evaluation is presented below as Table 3. Reasons for the evaluation follow thereafter. Space limitations confine the discussion to three of the six benefit segment evaluations. Reasons for these evaluations follow for the Pressure, Self Development and Career groups.

\section{PRESSURE GROUP}

With respect to university or program design, there are few unique features which deal directly with the benefits sought by this group. The smallness of the university as a whole and of its class sizes does appeal to a large segment of the pressure group. Laurentian has a far greater proportion of professional programs than most any other Ontario university and this is likely to address, at least in part, this group's particular need to "increase their standard of living". But as will be 
discussed later, few of Laurentian's programs are designed to allow for "more time to discover career interests and to formulate career plans," a particularly important benefit for this group.

Promotionally, Laurentian does a very good job of appealing to the Pressure segment. For example, its primary promotional booklet "The Laurentian Experience" states "Laurentian makes its students feel at home. It is an academic refuge for students who value the aesthetics of nature and learning in the serenity of the Northern Ontario environment" and also "Laurentian's friendly atmosphere curbs the loneliness of first year away from home" and as a testimonial "I wanted to go to the same university as my friends, one where they had good facilities, where I would meet new and interesting people."

\section{SELF DEVELOPMENT}

As will be recalled this benefit segment emphasizes the desire to improve general skills (e.g. problem solving, expression and communication, creativity skills), to achieve greater personal insight, to have more time to discover career interests, and to be exposed to more career opportunities. Though programs themselves are somewhat difficult to evaluate, it is clear from a review of Laurentian's promotional materials (program brochures, university brochures, university calendar and other advertising) that each of these benefits is very seldom mentioned and in particular that the "improve general skills" set of benefits is virtually ignored.

Whilst the university calendar is not the primary promotional tool, it certainly is the most comprehensive and is always sent to applicants for full-time study. In general, it does not mention benefits received from studying a subject or from attending university; the entries usually describe only the program requirements and the content (subject matter) of specific courses. Though there are some descriptions of specific areas of study, rarely does the calendar mention specific student need satisfaction. In particular, of the 42 program listings in the calendar, fifty-five percent make no mention of any benefits likely to accrue to the student from taking that program. Of the 19 which do mention one or more benefits, 10 include reference to the job market, 7 indicate the program provides "training", 5 talk of providing a broad educational base and 5 mention preparation for postgraduate work. Only 3 list freedom of choice or variety of programs, only two mention the advancement of knowledge and understanding.

If subject and course descriptions presented in the university's promotional materials are in fact a reasonable representation of program and course design then there is little in Laurentian's offering which appeals specifically to this benefit seeking segment.

\section{CAREER}

This group seeks above all else an improved standard of living through the opening up of greater career opportunities. They also require more time to discover their career interests. 
It is important to realize that members of this group do not have a clear understanding of what specific career they wish to pursue. They, for example, are not continuing to pursue their favourite subject. Once again the design of Laurentian's programs and the promotion of Laurentian does not seem to appeal particularly to this group. Although some promotional materials indicates the jobs such graduates might be prepared to enter upon graduation, no specific mention is ever made about the standard of living which may accompany such jobs. Moreover, in the appraisal of new programs, the standard of living of the graduates of such a program is not even considered. However, where graduates would be in high demand, the costs of hiring faculty to offer such programs is often much higher than average and may well work against the approval of such new programs.

Furthermore, many programs at Laurentian are designed in such a way that entering students must decide within the first few weeks of registration what program they intend to pursue for the next three to four years. For example, a student interested in the Sciences may have to make some very difficult course choices during his first week at Laurentian. If for example, he selects the Computer Science program, all 5 first year courses are compulsory and if he decides after the first year that Computer Science is not for him, he would only have taken the prerequisites which would allow him to pursue second year Mathematics or Physics. In other words, without summer make-up courses, the student could not enter (at the second year level) any of the Professional programs or even within the Sciences any other Science program such as Biology, Bio-Chemistry, Chemistry, Behavioral Neurology, Geology or Mining Geology. Moreover, for the student who wants to keep his options open, promotional and other materials (which are invariably program oriented, e.g.Chemistry) provide no guidance as to how that might be accomplished when it is possible.

\section{LIMITATIONS}

A serious limitation is that the survey was administered after the decision process had been completed. It therefore relies on the students' memory and it will be biased by the possible need for them to provide a rationalization of the choice they have already made. For most students the questionnaire was administered within three months of their final decision of which university to attend which will hopefully minimize these biases. It would be preferable, given the necessary resources, to study the students over an extended period of time whilst they are making the decisions concerning their choice of going to university, selection of universities and programs, and the final selection.

\section{Selected Implications for Laurentian}

The preceding evaluation clearly indicates that while Laurentian does serve some benefit segments reasonably well, it fails to serve others well. Such failure it should be noted does not result from a particular plan, strategic or otherwise, to 
target some benefit segments but not others. In the authors' view, it results almost totally from a lack of awareness of the existence of these various benefit segments.

If Laurentian is to attract more and better qualified students, improvements will have to be made in both program/university design and related promotion. Discussions with Laurentian's administrative officers concerning suitable promotion have resulted in a number of minor changes to the university's promotional materials (though not to the calendar itself); it is however too early to judge the success of such changes. To the authors' knowledge no progress has been made with respect to program structure or delivery. For example, no program changes have been made which would better serve those benefit segments seeking "more time to discover career interests and to formulate career plans."

The benefit segments discovered do not match the program offerings at Laurentian. Courses are typically designed to lead students towards increasing specialization within a discipline rather than serving the needs of identified market segments. The result is that the first year resembles a supermarket of introductory level courses designed for specialists. As an alternative, for example, Laurentian might think about mounting a program that is concerned with personal skill development and learning but which is not bound by any particular discipline.

Ideally Laurentian should develop separate promotional plans for each of the benefit segments it wishes to attract. In practice this is very difficult to do as the major sector consists of high school students who will be a mixture of all the segments, and it is not possible to separate out the desired groups. It may, therefore, be more effective for Laurentian's administrators to use the benefit dimensions as the basis for promotional appeals. If the University has a number of courses which focus on personal skill development it could emphasise this as a strength and thereby appeal to the segments for which this is an important factor. Alternatively if it sees its broad range of programs and courses as a strength it might choose to emphasise learning, discovering and intellectual development.

\section{CONCLUSIONS}

The research reported in this paper provides a case study of the application of market segmentation to the benefits sought by students at Laurentian University. The overall results appear to be sensible and they provide some insight into the motivations of those seeking a university education. The study demonstrates that it is possible to segment the educational market using measures of the benefits sought by students.

Other universities should undertake research using the approach advocated in this paper. This will enable them to discover the benefit segments for their student population. In turn, they can then provide the programs which best match the market segments and the resources of the university. 


\section{REFERENCES}

Cook, R. W. and Krampf, R. F. (1977). A nonmetric multidimensional scaling approach to the marketing of higher educational institutions. In Proceedings of the American Institute for Decision Sciences 9th Annual Conference (pp. 171-173).

Doyle, P. (1976). Marketing and the responsive university. Inaugural Lecture. Bradford, Yorkshire: University of Bradford.

Goodnow, W. E.. Increasing enrollment through market research. Unpublished Paper, Decatur, Illinois: Educational Marketing.

Green, P. E. and Tull, D. S. (1978). Research for marketing decisions (4th ed.). Englewood Cliffs, NJ: Prentice-Hall.

Heinlein, A.C. and Krampf, R. F. (1977). The effect of potential students' attitudes on enrollment decisions at a midwestern university. In Proceedings of the American Institute for Decision Sciences 9 th Annual Conference (pp. 377-339).

Kotler, P. and Dubois, B. (1974). Educational problems and marketing. In J. Sheth and P. Wright, (Eds.), Marketing analysis for social problems (pp. 186-206). Urbana, Illinois: University of Illinois.

Lynch, J. and Hooley, G. (1980). The University choice process. In M. J. Baker and M. A. Saren (Eds.), Marketing into the eighties: EAARM-MEG proceedings (pp. 222-246). Edinburgh: University of Strathclyde.

Morrison, D. G. (1967). On measurement problems in cluster analysis. Management Science, 12, $775-780$.

Morrison, D. G. (1976). Multivariate Statistical Methods (2nd ed.). New York: McGraw-Hill.

Punj, G. and Stewart, D. W. (1983). Cluster analysis in marketing research: Review and suggestions for application. Journal of Marketing Research, 20, 134-148.

Saunders, J. A. and Lancaster, G. A. (1980). The student selection process: A model of student courses in higher education. Working paper. University of Bradford, Bradford, Yorkshire.

Stewart, D. W. (1981). The application and misapplication of factor analysis in marketing research. Journal of Marketing Research, 18, 51-62.

Traynor, K. (1978). A benefit analysis of higher education using multiple discriminant analysis. In K. Hunk (Ed.) Advances in Consumer Research (pp. 129-133), Ann Arbor: Association for Consumer Research.

Vaughn, R., Pitlik, J. and Hansotia, B. (1978). Understanding university choice: A multi-attribute approach. In K. Hunk (Ed.) Advances in Consumer Research (pp. 26-31), Ann Arbor: Association for Consumer Research.

Watts, A. G. (1972). Diversity and choice in higher education. London: Routledge and Kegan Paul.

Wind, Yoram (1978). Issues and advances in segmentation research. Journal of Marketing Research, $15,317-337$. 